\title{
Essential oil composition of Strychnos axillaris Colebr. (Loganiaceae)
}

\author{
Wan Mohd Nuzul Hakimi Wan Salleh ${ }^{1, *}$, (D) Shamsul Khamis ${ }^{2}$, (D) Hakimi Kassim ${ }^{3}$ and (D) Alene \\ Tawang ${ }^{3}$ \\ ${ }^{1}$ Department of Chemistry, Faculty of Science and Mathematics, Universiti Pendidikan Sultan Idris (UPSI), 35900 Tanjung \\ Malim, Perak, MALAYSIA \\ ${ }^{2}$ School of Environmental and Natural Sciences, Faculty of Science and Technology, Universiti Kebangsaan Malaysia, \\ 43600 Bangi, Selangor, MALAYSIA \\ ${ }^{3}$ Department of Biology, Faculty of Science and Mathematics, Universiti Pendidikan Sultan Idris (UPSI), 35900 Tanjung \\ Malim, Perak, MALAYSIA
}

*Corresponding author. Email: wmnhakimi@fsmt.upsi.edu.my

Submitted: 07.09.2020; Accepted: 27.10.2020

\begin{abstract}
The essential oil composition from the leaves of Strychnos axillaris Colebr. (Loganiaceae) growing in Malaysia was examined for the first time. The essential oil was obtained by hydrodistillation and fully characterized by gas chromatography (GC-FID) and gas chromatography-mass spectrometry (GC-MS). In total, 15 components were identified in the essential oil, which made up $87.2 \%$ of the total oil. The essential is composed mainly of $\alpha$-ionone (20.2\%), $\beta$-ionone (19.5\%), bicyclogermacrene (19.2\%), and geranyl acetate (10.2\%).
\end{abstract}

Keywords: Loganiaceae, Strychnos axillaris, essential oil, ionone, GC-MS

\section{Introduction}

The Loganiaceae is a pantropical angiosperm family in the order Gentianales consisting of 16 genera and approximately 460 species, distributed in all tropical areas of the world, as well as reaching some subtropical areas (Francis and Suseem, 2016). The genus Strychnos, the largest genus of the family Loganiaceae, as tropical woody plants, consists of about 394 species. Meanwhile, 25 species occur in the Malaysian region. The flowers are small and usually white or creamy white in colour (Bisset, 1974). Several are important sources of drugs or poisons: strychnine, from the seeds of S. nux-vomica and other species; and curare, from the bark of S. toxifera and other species (Bisset and Phillipson, 1976). Strychnos was already being used medicinally in China in the $14^{\text {th }}$ Century. It has been prescribed as a stomachic, febrifuge, vermifuge, anticholeric and tonic and to treat sores, wounds, eczema and snake bites in Indonesia and the Philippines. In India, the seeds have been used to obstinate vomiting, to treat cholera, diarrhoea, asthma, dropsy, rheumatism, paralytic and neuralgic affections. In Australia, the fruit pulp of $S$. lucida has been used to treat a variety of skin complaints. S. wallichiana is used in Vietnam to treat rabies, leprosy, and as an aphrodisiac (Guo et al., 2018; Patel et al., 2017). S. axillaris is commonly known as gajah tarik in Malaysia. It grows naturally in woodlands, mixed forests, deciduous woodlands and lowlands. It has been used in Peninsular Malaysia in the preparation of arrow poison; its leaves have been used in India as a suppurative and the seeds internally as a febrifuge (Valadeau, 2010). The chemical analyses of S. axillaris revealed the presence of phenolic and iridoid glucosides (Itoh et al., 2008). Meanwhile, S. axillaris has not been previously studied for its essential oil. As a continuation part of our systematic evaluation of the aromatic flora of Malaysia (Salleh et al., 2014a, 2014b, 2014c, 2015, 2016a, 2016b, 2016c), we here report the volatile components of S. axillaris leaves. 


\section{Materials and Methods}

\section{Plant material}

Sample of Strychnos axillaris was collected from Gambang, Pahang in September 2019, and identified by Dr. Shamsul Khamis from Universiti Kebangsaan Malaysia (UKM). The voucher specimen (SK22/18) was deposited at UKMB Herbarium, Faculty of Science and Technology UKM.

\section{Isolation and analysis of essential oil}

The fresh leaf ( $340 \mathrm{~g}$ ) was subjected to hydrodistillation in Clevenger-type apparatus for 4 hours. The essential oil obtained was dried over anhydrous magnesium sulfate and stored at $4-6^{\circ} \mathrm{C}$.

Gas chromatography (GC-FID) analysis was performed on an Agilent Technologies 7890B equipped with HP5MS capillary column ( $30 \mathrm{~m}$ long, $0.25 \mu \mathrm{m}$ thickness and $0.25 \mathrm{~mm}$ inner diameter). Helium was used as a carrier gas at a flow rate of $0.7 \mathrm{~mL} / \mathrm{min}$. Injector and detector temperatures were set at 250 and $280^{\circ} \mathrm{C}$, respectively. The oven temperature was kept at $50^{\circ} \mathrm{C}$, then gradually raised to $280^{\circ} \mathrm{C}$ at $5^{\circ} \mathrm{C} / \mathrm{min}$ and finally held isothermally for $15 \mathrm{~min}$. Diluted samples (1/100 in diethyl ether, $\mathrm{v} / \mathrm{v})$ of $1.0 \mu \mathrm{L}$ were injected manually (split ratio 50:1). The injection was repeated three times and the peak area percent were reported as means $\pm S D$ of triplicates. Gas chromatography-mass spectrometry (GC-MS) analysis was recorded using a Hewlett Packard Model 5890A gas chromatography and a Hewlett Packard Model 5989A mass spectrometer. The GC was equipped with an HP-5 column. Helium was used as carrier gas at a flow rate of $1 \mathrm{~mL} / \mathrm{min}$. The injector temperature was $250^{\circ} \mathrm{C}$. The oven temperature was programmed from $50^{\circ} \mathrm{C}$ ( 5 min hold) to $280^{\circ} \mathrm{C}$ at $10^{\circ} \mathrm{C} / \mathrm{min}$ and finally held isothermally for $15 \mathrm{~min}$. For GC-MS detection, an electron ionization system, with ionization energy of $70 \mathrm{eV}$ was used. A scan rate of $0.5 \mathrm{~s}$ (cycle time: $0.2 \mathrm{~s}$ ) was applied, covering a mass range from 50-400 amu.

\section{Identification of components}

For identification of essential oil components, co-injection with the standards (major components) were used, together with correspondence of retention indices and mass spectra with respect to those reported in Adams (2007). Semi-quantification of essential oil components was made by peak area normalization considering the same response factor for all volatile components. Percentage values were the mean of three chromatographic analyses.

\section{Results and Discussion}

The list of chemical components identified in the essential oil is shown in Table 1. The essential oil yielded $0.17 \%$ calculated from the fresh weight of the leaves. The GC-FID (Figure 1) and GC-MS analysis of the essential oil revealed the presence of 15 chemical components with the composition of $87.2 \%$. The main fractions in the essential oil were sesquiterpene hydrocarbons $(58.9 \%)$, followed by oxygenated monoterpenes (19.5\%). The most abundant components of the essential oil were $\alpha$-ionone (20.2\%), $\beta$-ionone (19.5\%), bicyclogermacrene (19.2\%), and geranyl acetate (10.2\%). The other minor components detected in the essential oil in more than $2 \%$ were nerol (2.5\%), $\alpha$-terpineol $(2.4 \%),(E)$-nerolidol $(2.4 \%)$, linalool (2.2\%), geraniol (2.2\%) and eugenol (2.0\%). On the other hand, monoterpene hydrocarbons and oxygenated sesquiterpenes made up a minor fraction in the oil which constituted $1.3 \%$ and $2.4 \%$ of the total oil, respectively. The genus Strychnos is still poorly explored as far as its essential oil composition is concerned. A review of the existing literature on essential oils of the genus Strychnos revealed the presence of few studies reporting from S. spinosa (Hoet et al., 2006) and S. cocculoides (Shoko et al., 2013). In comparison to 
both studies, the leaf oil of S. spinosa was reported to show high amounts of palmitic acid (34.3\%), whereas the fruit oil of $S$. cocculoides gave isobutyl acetate $(53.2 \%)$ as the major component. However, these two components were not detected in the essential oil studied. The differences of the essential oil composition could be due to the different environmental and genetic factors, chemotypes and nutritional status of the plants, which may influence the oil composition (Salleh et al., 2016a).

Table 1. Chemical composition of Strychnos axillaris essential oil

\begin{tabular}{|c|c|c|c|c|c|}
\hline No. & $\mathbf{R} \mathbf{I}^{\mathbf{a}}$ & $\mathbf{R} \mathbf{I}^{\mathbf{b}}$ & Components & Percentage $^{c}$ & Identifications $^{d}$ \\
\hline 1 & 1014 & 1015 & $\alpha$-Terpinene & $0.5 \pm 0.1$ & $\mathrm{RI}, \mathrm{MS}$ \\
\hline 2 & 1025 & 1029 & Limonene & $0.8 \pm 0.1$ & $\mathrm{RI}, \mathrm{MS}$ \\
\hline 3 & 1095 & 1097 & Linalool & $2.2 \pm 0.2$ & $\mathrm{RI}, \mathrm{MS}$ \\
\hline 4 & 1185 & 1189 & $\alpha$-Terpineol & $2.4 \pm 0.2$ & $\mathrm{RI}, \mathrm{MS}$ \\
\hline 5 & 1240 & 1245 & Nerol & $2.5 \pm 0.1$ & $\mathrm{RI}, \mathrm{MS}$ \\
\hline 6 & 1271 & 1270 & Geraniol & $2.2 \pm 0.2$ & $\mathrm{RI}, \mathrm{MS}$ \\
\hline 7 & 1374 & 1375 & Eugenol & $2.0 \pm 0.1$ & $\mathrm{RI}, \mathrm{MS}$ \\
\hline 8 & 1435 & 1435 & $\alpha$-lonone & $20.2 \pm 0.1$ & $\mathrm{RI}, \mathrm{MS}$, Std \\
\hline 9 & 1497 & 1495 & $\beta$-Ionone & $19.5 \pm 0.1$ & RI, MS, Std \\
\hline 10 & 1529 & 1530 & Bicyclogermacrene & $19.2 \pm 0.2$ & $\mathrm{RI}, \mathrm{MS}$, Std \\
\hline 11 & 1563 & 1565 & (E)-Nerolidol & $2.4 \pm 0.2$ & $\mathrm{RI}, \mathrm{MS}$ \\
\hline 12 & 1700 & 1700 & Heptadecane & $0.5 \pm 0.1$ & $\mathrm{RI}, \mathrm{MS}$ \\
\hline 13 & 1720 & 1722 & Dodecanal & $1.1 \pm 0.1$ & $\mathrm{RI}, \mathrm{MS}$ \\
\hline 14 & 1758 & 1755 & Geranyl acetate & $10.2 \pm 0.1$ & $\mathrm{RI}, \mathrm{MS}$ \\
\hline \multirow[t]{7}{*}{15} & 1945 & 1940 & Phytol & $1.5 \pm 0.2$ & $\mathrm{RI}, \mathrm{MS}$ \\
\hline & & & Phenylpropanoid & $2.0 \pm 0.1$ & \\
\hline & & & Monoterpene hydrocarbons & $1.3 \pm 0.1$ & \\
\hline & & & Oxygenated monoterpenes & $19.5 \pm 0.2$ & \\
\hline & & & Sesquiterpene hydrocarbons & $58.9 \pm 0.2$ & \\
\hline & & & Oxygenated sesquiterpenes & $2.4 \pm 0.1$ & \\
\hline & & & Others & $3.1 \pm 0.1$ & \\
\hline
\end{tabular}

aLinear retention index, experimentally determined using homologous series of $\mathrm{C}_{6}-\mathrm{C}_{30}$ alkanes. ${ }^{\mathrm{b}}$ Linear retention index taken from Adams (2007). 'Relative percentage values are means of three determinations \pm SD. didentification methods: Std, based on comparison with authentic compounds; MS, based on comparison with Wiley, Adams, FFNSC2, and NIST08 MS databases; RI, based on comparison of calculated RI with those reported in Adams, FFNSC2 and NIST08.

Figure 1. GC chromatogram of Strychnos axillaris essential oil

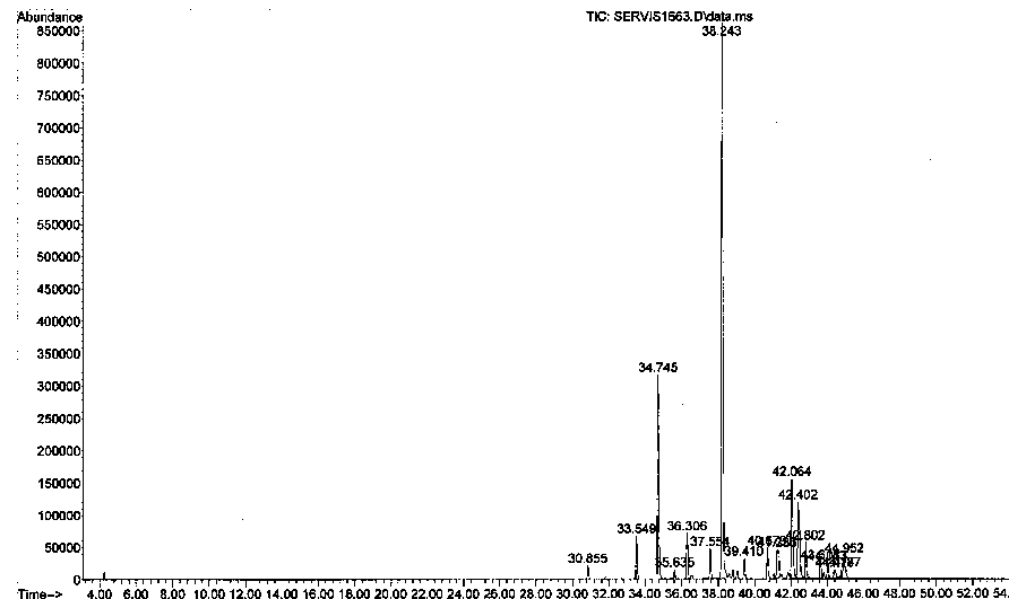


The presence of $\alpha$ - and $\beta$-ionone in the oil could be used as a chemotaxonomic marker for this species. These compounds are extensively used as ingredients and building blocks in flavors and fragrances, as well as in the pharmaceutical industry (Lalko et al., 2007). lonones and their derivatives are also known to possess important pharmacological properties, such as antileishmanial, anti-inflammatory, and antimicrobial activities (dos Santos Costa et al., 2007). In addition, recent studies have demonstrated the great potential of ionone derivatives as anticancer agents (Ansari and Emami, 2016). In conclusion, this is the first report of the chemical composition of the essential oil from Strychnos axillaris and the results of this study could contribute to the valorisation of this Malaysian aromatic and medicinal plant.

\section{ACKNOWLEDGMENT}

The authors would like to thank the Department of Chemistry, Faculty of Science and Mathematics, Universiti Pendidikan Sultan Idris for research facilities.

\section{CONFLICTS OF INTEREST}

The authors have no conflicts of interest to declare.

\section{REFERENCES}

Adams, R. P. (2007). Identification of essential oil components by gas chromatography/mass spectroscopy. Carol Stream (IL): Allured.

Ansari, M., Emami, S. (2016). $\beta$-lonone and its analogs as promising anticancer agents. European Journal of Medicinal Chemistry, 123, 141-154.

Bisset, N. G. (1974). The Asian species of Strychnos. Part III. The ethnobotany. Lloydia, 37(1), 62-107.

Bisset, N. G., Phillipson, J. D. (1976). The Asian species of Strychnos. Part IV. The alkaloids. Lloydia, 39(5), 263-325. dos Santos Costa, m., de Meireles, A. L. P., Gusevskaya, E. V. (2017). Aerobic palladium-catalyzed oxidations in the upgrading of biorenewables: oxidation of $\beta$-ionone and $\alpha$-ionone. Asian Journal of Organic Chemistry, 6(1), 1628-1634.

Francis, P., Suseem, S. R. (2016). A review on an endemic Indian species: Strychnos colubrina Linn. Research Journal of Pharmaceutical, Biological and Chemical Sciences, 7(1), 2021-2025.

Guo, R., Wang, T., Zhou, G., Xu, M., Yu, X., Zhang, X., Sui, F., Li, C., Tang, L., Wang, Z. (2018). Botany, Phytochemistry, Pharmacology and Toxicity of Strychnos nux-vomica L.: A Review. American Journal of Chinese Medicine, 46(1), 1-23.

Hoet, S., Stévigny, C., Hérent, M. F., Quetin-Leclercq, J. (2006). Antitrypanosomal compounds from the leaf essential oil of Strychnos spinosa. Planta Medica, 72(5), 480-482.

Itoh, A., Tanaka, Y., Nagakura, N., Akita, T., Nishi, T., Tanahashi, T. (2008). Phenolic and iridoid glycosides from Strychnos axillaris. Phytochemistry, 69(5), 1208-1214.

Lalko, J., Lapczynski, A., McGinty, D., Bhatia, S., Letizia, C., Api, M. (2007). Fragrance material review on trans- $\beta$-lonone. Food and Chemical Toxicology, 45(1), 248-250.

Patel, K., Laloo, D., Singh, G. K., Gadewar, M., Patel, D. K. (2017). A review on medicinal uses, analytical techniques and pharmacological activities of Strychnos nux-vomica Linn.: A concise report. Chinese Journal of Integrative Medicine, 113.

Salleh, W. M. N. H. W., Ahmad, F., \& Khong, H. Y. (2014a). Chemical compositions and antimicrobial activity of the essential oils of Piper abbreviatum, P. erecticaule and P. Ianatum (Piperaceae). Natural Product Communications, 9(12), 1795-1798. 
Salleh, W. M. N. H. W., Ahmad, F., \& Khong, H. Y. (2014b). Chemical composition of Piper stylosum Miq. and Piper ribesioides Wall. essential oils and their antioxidant, antimicrobial and tyrosinase inhibition activities. Boletin Latinoamericano y del Caribe de Plantas Medicinales y Aromaticas, 13(5), 488-497.

Salleh, W. M. N. H. W., Ahmad, F., \& Khong, H. Y. (2014c). Antioxidant and anti-tyrosinase activities from Piper officinarum C.DC (Piperaceae). Journal of Applied Pharmaceutical Sciences, 4(5), 87-91.

Salleh, W. M. N. H. W., Kamil, F., Ahmad, F., \& Sirat, H. M. (2015). Antioxidant and anti-inflammatory activities of essential oil and extracts of Piper miniatum. Natural Product Communications, 10(11), 2005-2008.

Salleh, W. M. N. H. W., \& Ahmad, F. (2016a). Antioxidant and anti-inflammatory activities of essential oils of Actinodaphne macrophylla and A. pruinosa (Lauraceae). Natural Product Communications, 11(6), 853-855.

Salleh, W. M. N. H. W., Ahmad, F., Khong, H. Y., \& Zulkifli, R. M. (2016b). Essential oil composition of Malaysian Lauraceae: A mini review. Pharmaceutical Sciences, 22(1), 60-67.

Salleh, W. M. N. H. W., Ahmad, F., Khong, H. Y., Zulkifli, R. M., Sarker, S. D. (2016c). Madangones A and B: Two new neolignans from the stem bark of Beilschmiedia madang and their bioactivities. Phytochemistry Letters, 15, 168-173.

Shoko, T., Apostolides, Z., Monjerezi, M., Saka, J. D. K. (2013). Volatile constituents of fruit pulp of Strychnos cocculoides (Baker) growing in Malawi using solid phase microextraction. South African Journal of Botany, 84, 11-12.

Valadeau, C., Castillo, J. A., Sauvain, M., Lores, A. F., Bourdy, G. (2010). The rainbow hurts my skin: Medicinal concepts and plants uses among the Yanesha (Amuesha), an Amazonian Peruvian ethnic group. Journal of Ethnopharmacology, 127, 175-192. 